\title{
Supporting Information for optical detection of stereoselective interactions with DNA-wrapped single-wall carbon nanotubes
}

Zeus A. De los Santos*, Zhiwei Lin, and Ming Zheng

Materials Science and Engineering Division, National Institute of Standards and Technology, 100 Bureau Drive, Gaithersburg, MD 20899, United States

\section{Disclaimer:}

Certain equipment, instruments or materials are identified in this paper in order to adequately specify the experimental details. Such identification does not imply recommendation by the National Institute of Standards and Technology (NIST), nor does it imply the materials are necessarily the best available for the purpose. Official contribution of the National Institute of Standards and Technology, not subject to copyright in the United States.

\section{Table of Contents}

I. Materials 2

II. Purification of $(+)$ and $(-)(6,5),(-)(8,3)$ and $(11,0) \quad 2$

III. UV-Visible-near infrared (UV-Vis-nIR) absorption 3 and circular dichroism (CD) spectroscopy

$\begin{array}{lll}\text { IV. } & \text { Structures of amino acids used in this study } & 7\end{array}$

V. $\quad$ ssDNA selection for SWCNT dispersion $\quad 8$

VI. Titration assay $\quad 9$

$\begin{array}{ll}\text { VII. Amino acid assay } & 10\end{array}$

VIII. Response spectrum calculated to show chirality-dependence 20 response when TTA (TAT) 2 ATT-SWCNT was treated with tryptophan (Trp) (top) and serine (Ser) (bottom) enantiomers

IX. References 


\section{Materials}

Cobalt-Molybdenum catalyst (CoMoCAT) SWCNT powders (SG65i grade, lot no. SG65i-L46) were obtained from Chasm Nanotechnology. Oligomers of ssDNA were purchased from Integrated DNA Technologies. Polyethylene glycol (PEG, MW 6 kDa, (Alfa Aesar), potassium sodium L-tartrate tetrahydrate (Sigma-Aldrich), sodium phosphate buffer solution $(1.0 \mathrm{~mol} / \mathrm{L}, \mathrm{pH}$ $7.4\left(25^{\circ} \mathrm{C}\right)$, Sigma-Aldrich), L-phenylalanine (ICN Biomedicals), D-phenylalanine (ICN Biomedicals), L-tryptophan (ICN Biomedicals), D-tryptophan (Sigma-Aldrich), L-tyrosine (ICN Biomedicals), D-tyrosine (ICN Biomedicals), L-serine (Fluka), D-serine (Sigma-Aldrich), Lthreonine (ICN Biomedicals), D-threonine (ICN Biomedicals), L-valine (ICN Biomedicals), Dvaline (Acros Organics), L-cysteine (Fluka), D-cysteine (Alfa Aesar), L-aspartic acid (TCI Chemicals), D-aspartic acid (TCI Chemicals), L-lysine monohydrochloride (VWR), and D-lysine monohydrochloride (Alfa Aesar) were used as received. DNA-SWCNT dispersions were prepared according to the previously published procedures. ${ }^{1,2}$ Briefly, CoMoCAT SWCNT powders were dispersed $(1 \mathrm{mg} / \mathrm{mL}$ ) in aqueous solution of DNA (mass ratio SWCNT:DNA is 1:2.5) and $\mathrm{NaCl}$ $(30 \mathrm{mmol} / \mathrm{L})$ by tip sonication. The amino acids were dissolved in $200 \mathrm{mmol} / \mathrm{L}$ sodium phosphate buffer $(\mathrm{NaPB})$ at $\mathrm{pH} 7.4$ to make $0.2 \mathrm{mmol} / \mathrm{L}$ stock solutions.

\section{Purification of $(+)$ and $(-)(6,5),(-)(8,3)$ and $(11,0)$}

DNA-SWCNT dispersions were prepared according to the procedures reported previously. ${ }^{1,3}$ Typically, SG65i-L64 SWCNT powders $(1 \mathrm{mg})$ and ssDNA sequence $(2.5 \mathrm{mg})$ are sonicated in either sodium phosphate buffer $\left(\mathrm{GC}_{13} \mathrm{G}-\mathrm{SWCNT}, 30 \mathrm{mmol} / \mathrm{L}\right.$ at $\left.\mathrm{pH}=4\right)$ or sodium chloride in aqueous solution (TTA (TAT) $)_{2}$ ATT-(-)(6,5) and $\mathrm{T}_{3} \mathrm{C}_{3} \mathrm{~T}_{3} \mathrm{C}_{6}-(-)(8,3), 30 \mathrm{mM}$ at $\mathrm{pH}=7$ ), giving 1 $\mathrm{mg} / \mathrm{mL}$ of SWCNT-DNA dispersion. For the purification of TTA $(\text { TAT })_{2}$ ATT- $(-)(6,5)$ and $\mathrm{T}_{3} \mathrm{C}_{3} \mathrm{~T}_{3} \mathrm{C}_{6}-(-)(8,3)$, the following procedure was followed. ${ }^{4}$ Separate ATP stock solutions of PEG $6 \mathrm{kDa}$ (40\% mass/mass) and KNaTartrate tetrahydrate (40\% mass/mass) denoted by 10:0 and 7:3 were prepared. The 10:0 stock solution was prepared by combining $5.5 \mathrm{~mL}$ of $40 \%$ mass $/ \mathrm{mass}$ KNaTartrate tetrahydrdate, $5.0 \mathrm{~mL}$ of $40 \%$ mass/mass PEG $6 \mathrm{kDa}$ and $5.5 \mathrm{~mL}$ deionized water. The $7: 3$ stock solution was prepared by mixing $3.3 \mathrm{~mL}$ of $40 \%$ mass/ mass KNaTartrate tetrahydrate, $3.0 \mathrm{~mL} \mathrm{40 \%} \mathrm{mass/mass} \mathrm{PEG} 6 \mathrm{kDa}$ and $0.4 \mathrm{~mL}$ of deionized water. The 10:0 and 7:3 stock solution designations are discussed more in detail in our previous work. ${ }^{2}$ In a typical separation, $60.0 \mu \mathrm{L}$ (3 volumes) of DNA-SWCNT dispersion was added into $140.0 \mu \mathrm{L}$ ( 7 volumes) of 7:3 PEG/KNaTartrate tetrahydrate stock solution. The mixture was vortexed and was subsequently centrifuged to allow for phase separation. The top phase containing purified enantiomers of either TTA (TAT) $)_{2}$ ATT $-(-)(6,5)$ or $\mathrm{T}_{3} \mathrm{C}_{3} \mathrm{~T}_{3} \mathrm{C}_{6}-(-)(8,3)$ was extracted (roughly 100 $\mu \mathrm{L})$. Additional 100.0 $\mu \mathrm{L}$ of the top phase of 10:0 stock solution was added to the bottom phase from the previous extraction to obtain more of the enantioenriched DNA-SWCNT. The mixture was vortexed, and the top phase was collected. Multiple separations were performed to obtain enough material for analyses in this work. After obtaining enough material, combined fractions containing enantiopure DNA-SWCNTs in PEG/salt solution were treated with NaSCN to a final concentration of $0.5 \mathrm{M}$ and was incubated for 18 hours at $4{ }^{\circ} \mathrm{C}$. The precipitated tubes were centrifuged at $17,000 \mathrm{G}\left(\mathrm{G}=9.81 \mathrm{~m} / \mathrm{s}^{2}\right)$ for 15 minutes and the supernatant liquid was separated from the pellet. The pelleted DNA-SWCNTs were then redispersed in deionized $\mathrm{H}_{2} \mathrm{O}$ (typically $1.0 \mathrm{~mL}$ ) and were treated with the corresponding DNA to a final concentration of $30 \mu \mathrm{g} / \mathrm{mL}$ for further SWCNT dispersion stabilization. ${ }^{4}$ 
For the purification of $\mathrm{GC}_{13} \mathrm{G}-(11,0)$, the following procedure was followed. Separate solutions of PEG, 1.5 kDa and Dextran 250 kDa ATP stock solution (with two compositions 10:0 and 7:3) following the procedures identified in our previous publication. ${ }^{2}$ The mass fraction of PEG, $1.5 \mathrm{kDa}$ and Dextran, 250kDa are 8.57 and 10.1 in 10:0 stock solution, and 12.2 and 14.4 in 7:3 stock solution, respectively. In a typical partition experiment, 3 volumes $(120.0 \mu \mathrm{L})$ of SWCNT-DNA dispersion were loaded into 7 volumes $(280.0 \mu \mathrm{L})$ of the 7:3 stock solution, giving a 10:0 ATP system at room temperature. In the first step, $1.5 \mu \mathrm{L} 1 \%$ volume/volume polyvinylpyrrolidone (10 $\mathrm{kDa})$ in water was added into the 10:0 ATP system. The mixture was vortexed and was subsequently centrifuged and the first top fraction $(1 \mathrm{~T})$ was extracted. $1 \mathrm{~T}$ fraction containing $(11,0)$ species was further incubated at $4{ }^{\circ} \mathrm{C}$ overnight, inducing a new two-phase separation. The new top fraction $(1 \mathrm{~T}-\mathrm{T})$ with a higher purity of $(11,0)$ species was collected and the $\mathrm{GC}_{13} \mathrm{G}-(11,0)$ hybrids were precipitated by adding NaSCN to reach a final salt concentration of $0.5 \mathrm{~mol} / \mathrm{L}$. The pellets were resuspended in deionized $\mathrm{H}_{2} \mathrm{O}$ (typically $1.0 \mathrm{~mL}$ ) and were treated with the corresponding DNA to a final concentration of $30 \mu \mathrm{g} / \mathrm{mL}$ for further SWCNT dispersion stabilization.

Purification of TTA (TAT) $)_{2}$ ATT- $(+)(6,5)$ SWCNT involved DNA exchange from $\mathrm{GC}_{4} \mathrm{G}-(+)(6,5)$ to TTA (TAT) $)_{2}$ ATT-(+)(6,5). Separate solutions of PEG, $1.5 \mathrm{kDa}$ and Dextran $250 \mathrm{kDa}$ ATP stock solution (with two compositions 10:0 and 7:3) were prepared following the procedures identified in our previous publication. ${ }^{2}$ The mass fraction of PEG, $1.5 \mathrm{kDa}$ and Dextran, 250kDa are 8.57 and 10.1 in 10:0 stock solution, and 12.2 and 14.4 in 7:3 stock solution, respectively. In a typical partition experiment, 3 volumes $(120 \mu \mathrm{L})$ of SWCNT-DNA dispersion were loaded into 7 volumes $(280 \mu \mathrm{L})$ of the 7:3 stock solution, giving a 10:0 ATP system at room temperature. In the first step, $1.5 \mu \mathrm{L} \mathrm{1 \%}$ polyvinylpyrrolidone $(10 \mathrm{kDa})$ in water was added into the 10:0 ATP system. The mixture was vortexed and was subsequently centrifuged and the first top fraction (1T) was extracted. $1 \mathrm{~T}$ fraction containing $(+)(6,5)$ species was further incubated at $4{ }^{\circ} \mathrm{C}$ overnight, inducing a new two-phase separation. The new top fraction (1T-T) with a higher purity of $(+)(6,5)$ species was collected and the $\mathrm{GC}_{4} \mathrm{G}-(+)(6,5)$ hybrids were precipitated by adding $\mathrm{NaSCN}$ to a final concentration of $0.5 \mathrm{M}$. The pellets were resuspended in deionized $\mathrm{H}_{2} \mathrm{O}$ (typically $0.20 \mathrm{~mL}$ ) and was treated with sodium deoxycholate (DOC) to a final concentration of $1 \%$ volume/volume. Excess $\mathrm{GC}_{4} \mathrm{G}$ DNA was removed using a $30 \mathrm{kDa}$ spin filter. The DOC-coated $(+)(6,5)$ was resuspended in $0.2 \mathrm{~mL}$ deionized water and was treated with $5 \mu \mathrm{L}$ of $10 \mathrm{mg} / \mathrm{mL}$ solution of TTA $(\mathrm{ATT})_{2}$ ATT. The solution was then very slowly treated with $0.2 \mathrm{~mL}$ of methanol with subsequent vigorous mixing. The precipitated TTA $(\text { TAT })_{2}$ ATT- $(+)(6,5)$ were centrifuged at $17,000 \mathrm{G}(\mathrm{G}=$ $\left.9.81 \mathrm{~m} / \mathrm{s}^{2}\right)$ for 15 minutes and the supernatant liquid was separated from the pellet. The pelleted DNA-SWCNTs were then redispersed in deionized $\mathrm{H}_{2} \mathrm{O}$ (typically $1.0 \mathrm{~mL}$ ) and were treated with the corresponding DNA to a final concentration of $30 \mu \mathrm{g} / \mathrm{mL}$ for further SWCNT dispersion stabilization. ${ }^{4}$

\section{UV-Visible-near infrared (UV-Vis-nIR) absorption and CD spectroscopy}

UV-Vis-NIR absorption spectra were collected on a Cary 5000 spectrophotometer from 300 to $1350 \mathrm{~nm}$ using a $1 \mathrm{~cm}$ path length quartz microcuvette with $130 \mathrm{mmol} / \mathrm{L} \mathrm{NaPB}(\mathrm{pH}=7.4)$ used as the reference for baseline. CD spectra were recorded with an OLIS DSM 1000 CD spectrophotometer, covering a range of 300 to $750 \mathrm{~nm}$. All CD spectra were measured using 1.5 $\mathrm{nm}$ spectral steps with a $2 \mathrm{~mm}$ path length. The $\mathrm{CD}$ spectra were corrected using the $\mathrm{E}_{22}$ absorption 


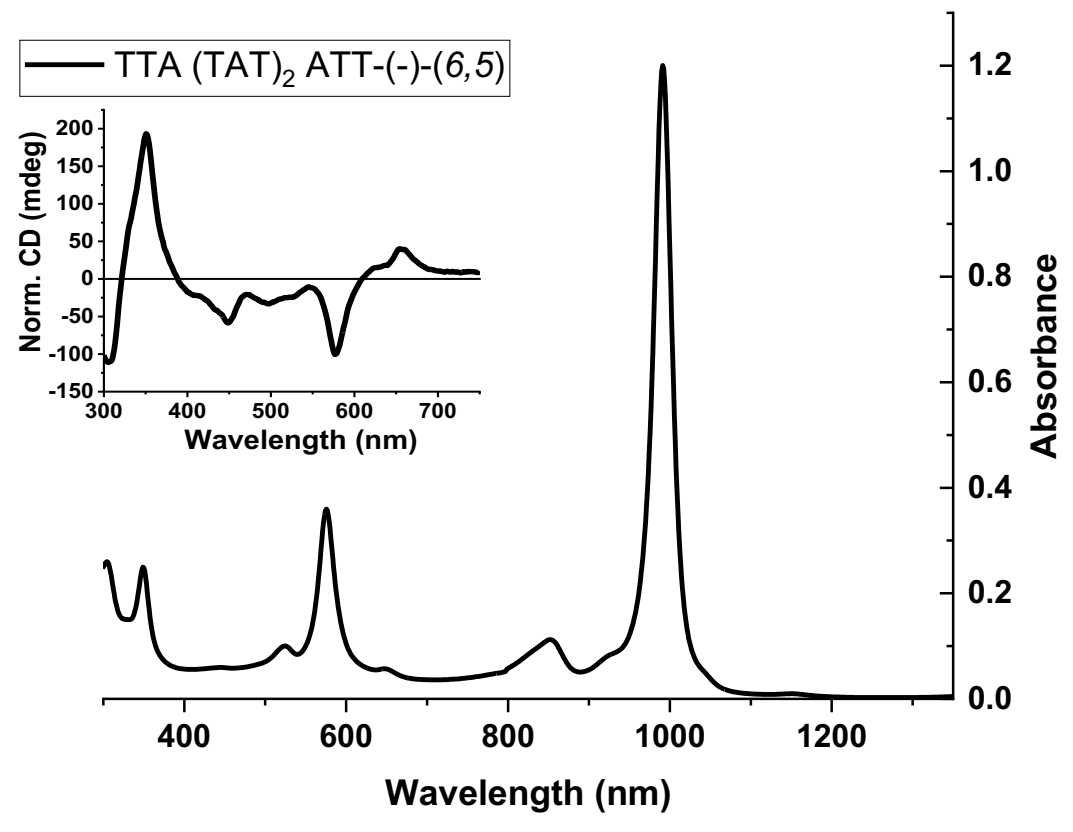

Figure S1 UV-Visible-near infrared and CD spectrum (inset) of purified TTA $($ TAT) 2 ATT-(-)(6,5).

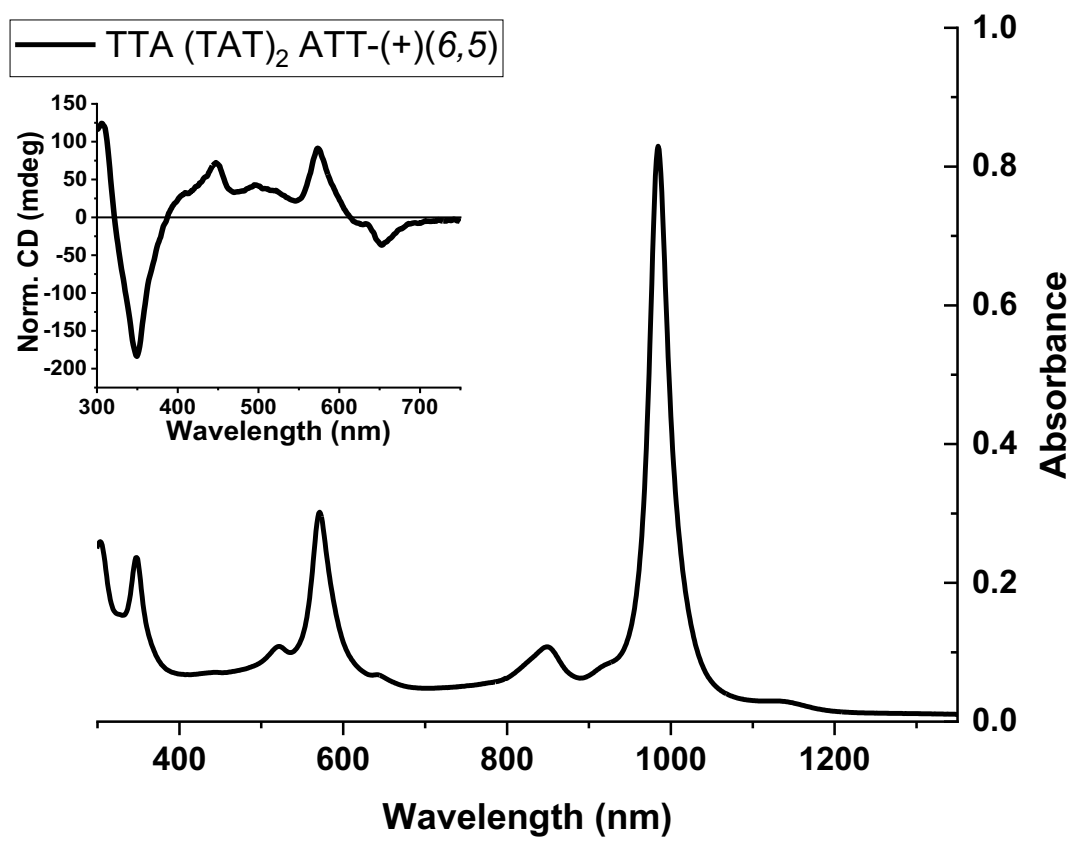

Figure S2 UV-Visible-near infrared and CD spectrum (inset) of purified TTA (TAT) 2 ATT-(+)(6,5). 


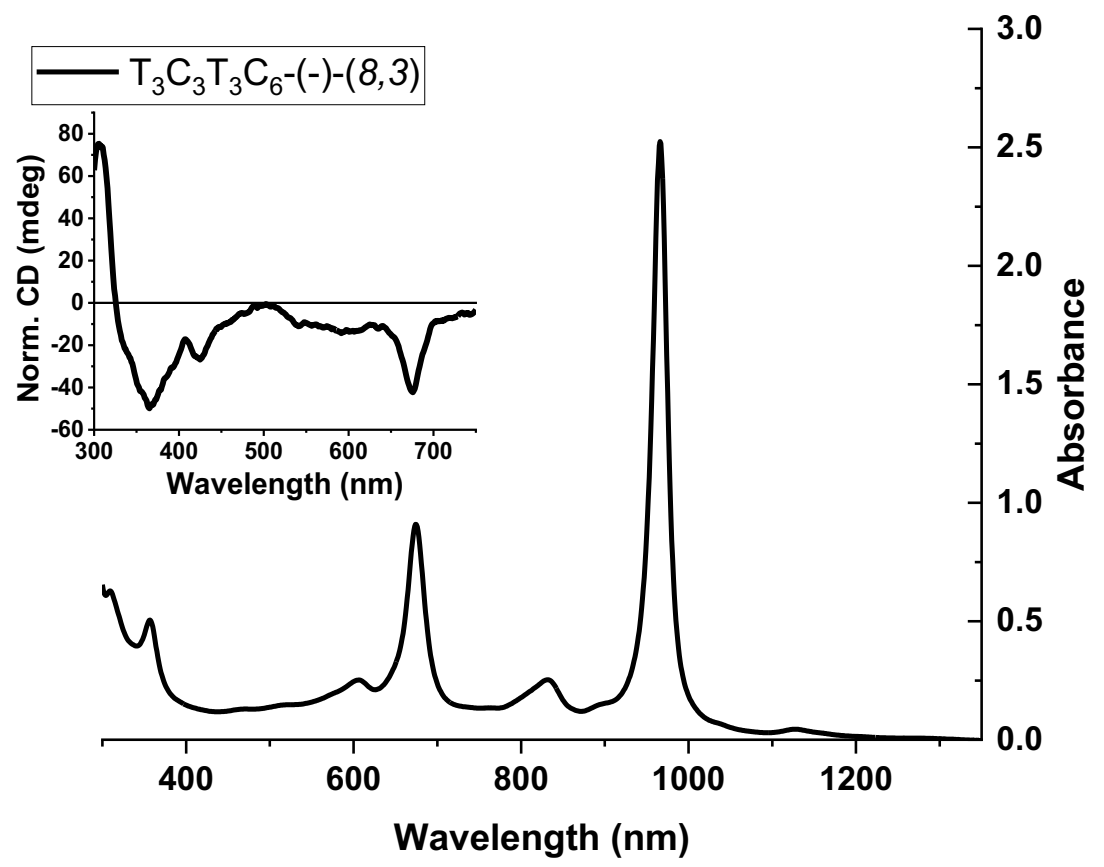

Figure S3 UV-Visible-near infrared and CD spectrum (inset) of purified $\mathrm{T}_{3} \mathrm{C}_{3} \mathrm{~T}_{3} \mathrm{C}_{6}-(-)(8,3)$.

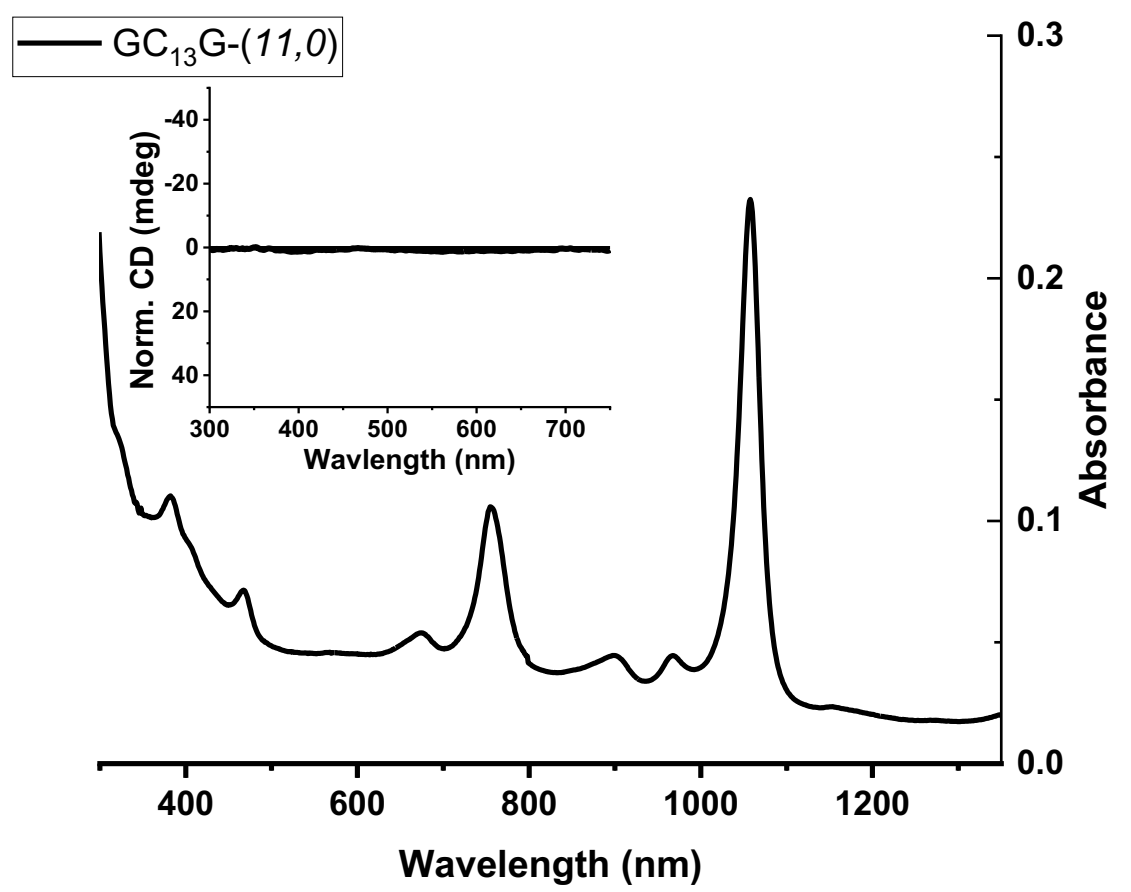

Figure S4 UV-Visible-near infrared and CD spectrum (inset) of purified $\mathrm{GC}_{13} \mathrm{G}-(11,0)$. 


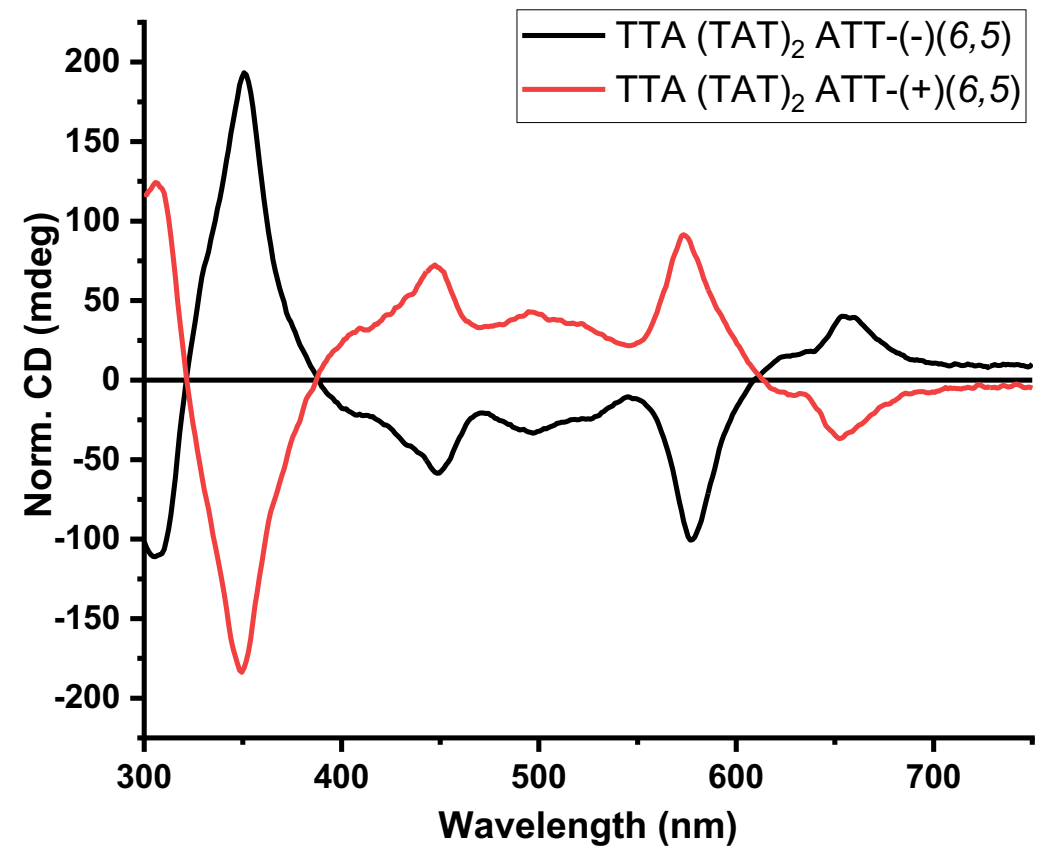

Figure S5 Combined CD spectra of purified TTA (TAT) $)_{2}$ ATT-(+) and (-)(6,5). 
IV. Structures of amino acids used in this study<smiles>N[C](Cc1ccccc1)C(=O)O</smiles><smiles>N[C@@H](Cc1c[nH]c2ccccc12)C(=O)O</smiles><smiles>N[C@@H](Cc1ccc(O)cc1)C(=O)O</smiles><smiles>N[C@@H](CO)C(=O)O</smiles><smiles>C[C@H](O)[C@H](N)C(=O)O</smiles><smiles>N[C@@H](CS)C(=O)O</smiles>
Tyrosine

Threonine

Cysteine<smiles>CC(C)[C@H](N)C(=O)O</smiles><smiles>N[C@@H](CC(=O)[O-])C(=O)O</smiles><smiles>N[C@@H](CCCCC([NH3+])C(=O)O)C(=O)O</smiles>

Aspartate

Lysine

Figure S6 Structures of the chiral amino acids used in this study. 


\section{V. ssDNA selection for SWCNT dispersion}

In choosing ssDNA sequences to wrap SWCNTs with, the primary consideration is the ability of a sequence to resolve SWCNT species in aqueous two-polymer phase sorting experiments. This type of sequence, termed a resolving sequence, ${ }^{2}$ is presumably capable of forming an ordered wrapping structure on at least some SWCNT specie(s) to enable separation. There are over 100 resolving sequences discovered so far, and they are frequently used for DNA-SWCNT based sensing applications. This set provides a large pool of candidates to select from. Ultimately, five resolving sequences: TTA (TAT) $)_{2}$ ATT, $\mathrm{T}_{3} \mathrm{C}_{3} \mathrm{~T}_{3} \mathrm{C}_{6}, \mathrm{GC}_{13} \mathrm{G},(\mathrm{GT})_{6},(\mathrm{GT})_{20}$ plus a random 12-mer sequence were chosen for this study; the first two sequences because of their ability to resolve $(6,5)$ and $(8,3)$ enantiomers. ${ }^{1,2}$ C-rich sequences, such as $\mathrm{GC}_{11}$, were previously found to form inter-strand hydrogen bonding that enables purification of some $\mathrm{SWCNT}$ chiralities, ${ }^{2} \mathrm{GC}_{13} \mathrm{G}$ (purifies $(11,0)$ ) was chosen as a representative C-rich sequence for this study. $(\mathrm{GT})_{6}$ and $(\mathrm{GT})_{20}$ are resolving sequences identified through SWCNT sorting experiments. ${ }^{3,5,6}$ Many researchers have used poly-GT sequences in sensing of small molecules such as dopamine and nitric oxide. ${ }^{7-}$ ${ }^{10}$ Lastly, we decided to include a random12-mer comprising of a population of 12 base-long sequences in which each position of a sequence has equal probability of being one of the four bases $\mathrm{G}, \mathrm{A}, \mathrm{T}, \mathrm{C}$. We use this sequence to test if ssDNA in general would adopt a preferred chiral wrapping conformation on nanotubes as suggested by a recent computational study ${ }^{11}$ and give rise to stereoselective PL from the corresponding DNA-SWCNT dispersion.

Table S1 ssDNA sequences used to wrap SWCNTs with and the corresponding carbon nanotube structures they can resolve.

\begin{tabular}{|c|c|}
\hline ssDNA sequences & Resolving sequence to sort $(\boldsymbol{n}, \boldsymbol{m})$ \\
\hline $\mathrm{TTA}(\mathrm{TAT})_{2} \mathrm{ATT}$ & $(+)$ and $(-)(6,5)$ \\
\hline $\mathrm{T}_{3} \mathrm{C}_{3} \mathrm{~T}_{3} \mathrm{C}_{6}$ & $(+)$ and $(-)(8,3)$ \\
\hline $\mathrm{GC}_{13} \mathrm{G}$ & $(11,0)$ \\
\hline$(\mathrm{GT})_{6}$ & $( \pm)(8,6)$ \\
\hline$(\mathrm{GT})_{20}$ & Diameter sorting, $(5,5),(-)(8,4),( \pm)(7,4)$ \\
\hline Random $12-\mathrm{mer}$ & - \\
\hline
\end{tabular}




\section{Titration assay}

To a $0.5 \mathrm{~mL}$ solution of TTA (TAT) $)_{2}$ ATT-(-)(6,5) $(\sim 1 \mu \mathrm{g} / \mathrm{mL})$ in $130 \mathrm{mmol} / \mathrm{L} \mathrm{NaPB}(\mathrm{pH}=7.4)$, increasing volumes of $2.0 \mathrm{mmol} / \mathrm{L} \mathrm{L}$-Phe (red) or D-Phe (blue) in $130 \mathrm{mmol} / \mathrm{L} \mathrm{NaPB}(\mathrm{pH}=7.4)$ were added. After each addition, the resulting solution was stirred and subjected to PL analysis as described above. The observed PL intensity was corrected linearly based on the recorded laser power and the incremental volume change when the substrates were added, and was subsequently normalized against the PL spectrum of the TTA (TAT) 2 ATT-(-) $(6,5)$ that was not treated with Phe. The measured curves were fitted using the Hill equation ${ }^{12}$ with a Hill coefficient $=1$ to yield effective binding constants for L-Phe $(22.2 \pm 4.0 \mu \mathrm{mol} / \mathrm{L})$ and D-Phe $(4.8 \pm 0.7 \mu \mathrm{mol} / \mathrm{L})$. The titration data were fit to the following Hill equation using a fitting routine in Sigmaplot:

$$
I=I_{0}+a \frac{[P h e]^{n}}{C^{n}+[P h e]^{n}}
$$

with $I_{0}=1$, and $n=1$ (i.e., first-order Hill equation). The fitting procedure yielded the binding constant $\mathrm{c}$ and an error bar associated with it.

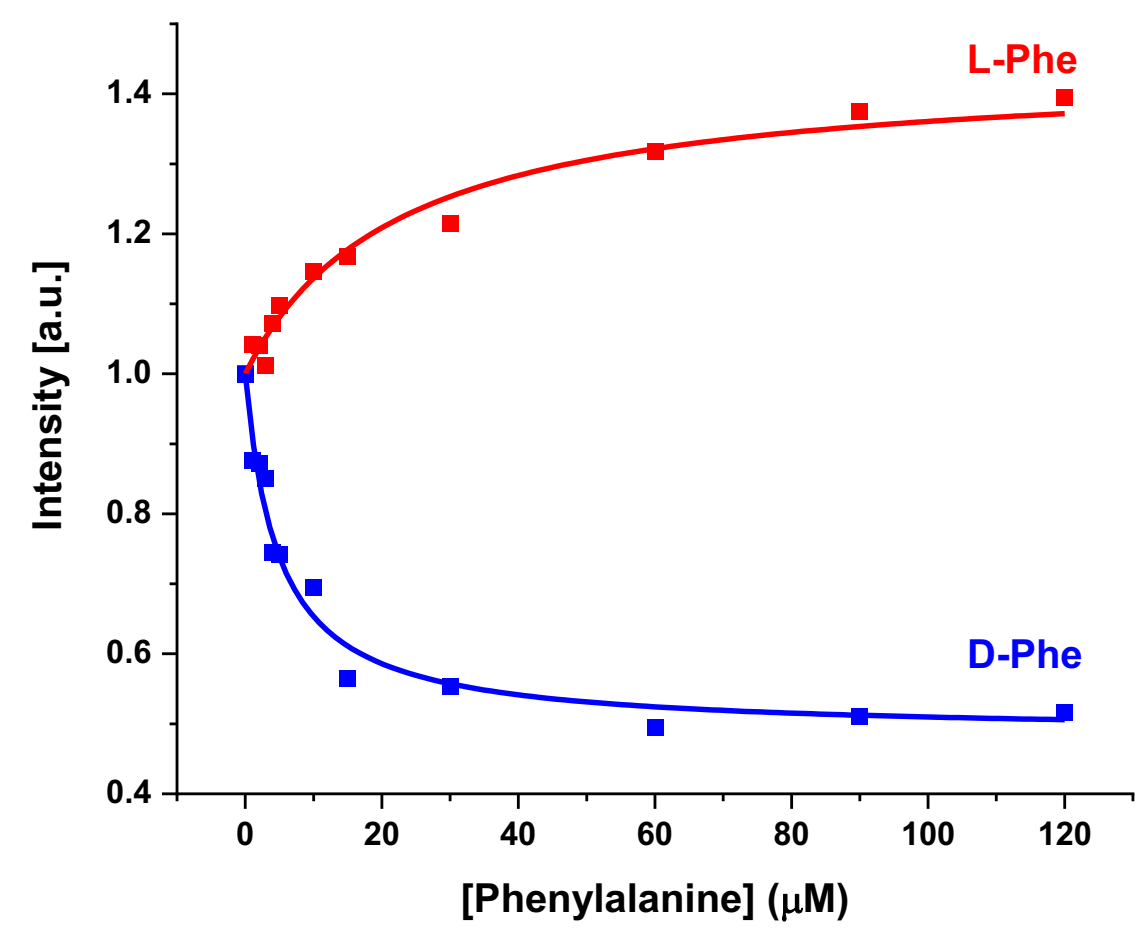

Figure S7 Titration plot of TTA (TAT) 2 ATT-(-)(6,5) when treated with L (red) or D-Phe (blue). 


\section{Amino acid assay}

For a typical amino acid assay, SWCNT dispersions are added into $20 \mathrm{mmol} / \mathrm{L} \mathrm{NaPB}$ at $\mathrm{pH} 7.4$ (OD at $990 \mathrm{~nm} \approx 0.1$, around $1 \mu \mathrm{g} / \mathrm{mL}$ ). A volume of $0.2 \mathrm{~mL}$ of this solution is transferred into a $1.5 \mathrm{~mL}$ centrifuge tube and subsequently treated with $0.3 \mathrm{~mL}$ of $0.2 \mathrm{mmol} / \mathrm{L}$ amino acid dissolved in $200 \mathrm{mmol} / \mathrm{L} \mathrm{NaPB}$ at $\mathrm{pH} 7.4$, to make a $0.5 \mathrm{~mL}$ solution that has nanotube concentration of OD at $990 \mathrm{~nm} \approx 0.1$, amino acid concentration of $0.12 \mathrm{mmol} / \mathrm{L}$, and $\mathrm{NaPB}(\mathrm{pH}=7.4)$ concentration of $0.13 \mathrm{mmol} / \mathrm{L}$ to ensure saturation. This corresponds to a total amino acid:nucleobase ratio of $\sim$ 24:1. The solutions are stirred and immediately analyzed for NIR-fluorescence using an NS3 Nanospectralyzer (Applied NanoFluorescence, Houston, TX) with multiple excitation wavelengths $(532,671$, and/or $782 \mathrm{~nm})$. The volume for each analysis was typically $0.4 \mathrm{~mL}$ and all PL spectra were obtained at ambient room temperature. The observed PL intensity was collected under specific conditions listed above and were corrected linearly based on the recorded laser power and subsequently normalized against the PL spectrum of the parent SWCNT dispersion that was not treated with any exogenous substrates.

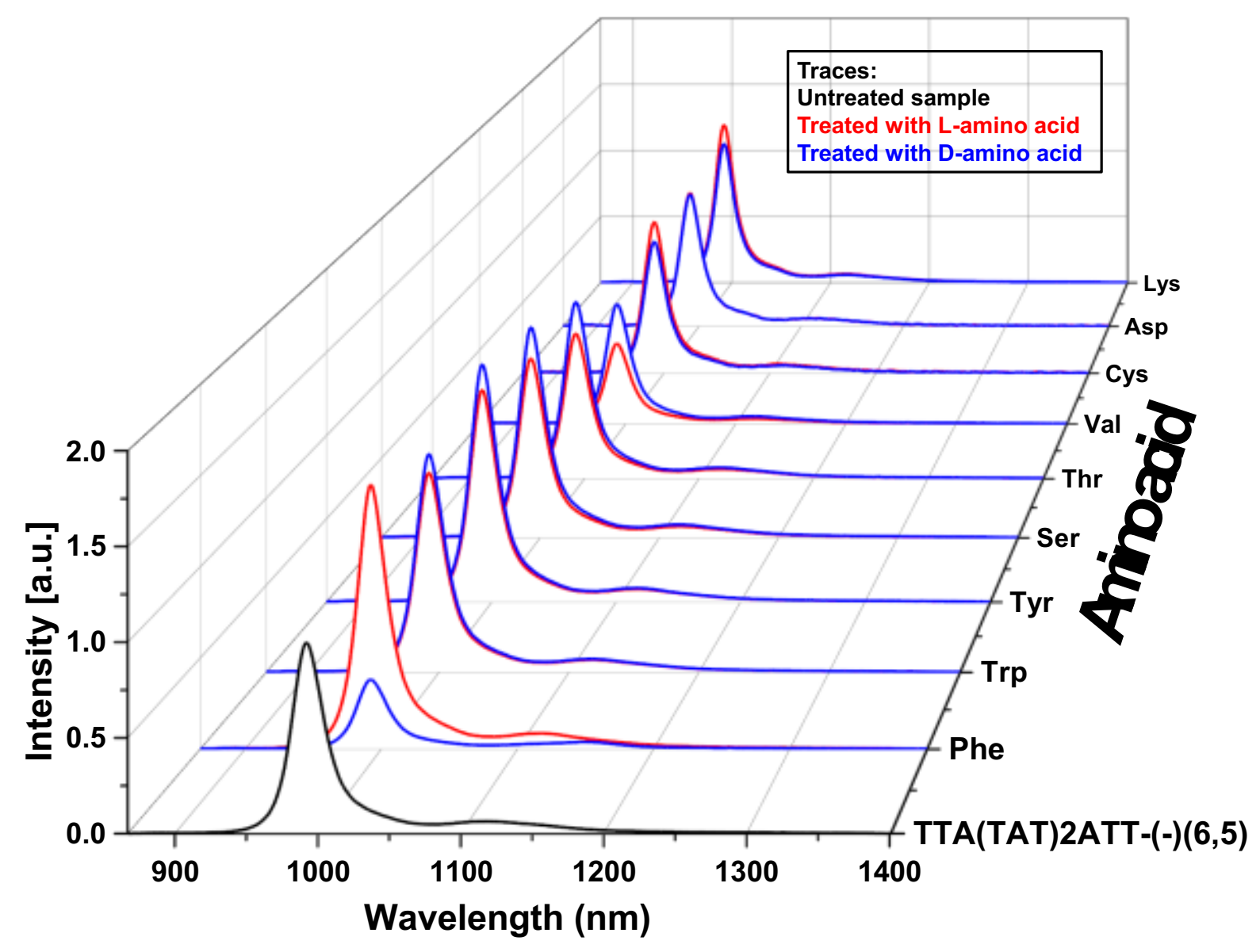

Figure S8 Waterfall plot of diastereomerically pure TTA(TAT) $)_{2}$ ATT-(-)(6,5) when treated with enantiomeric amino acids (excitation wavelength $=\mathbf{5 3 2} \mathbf{~ n m})$. 


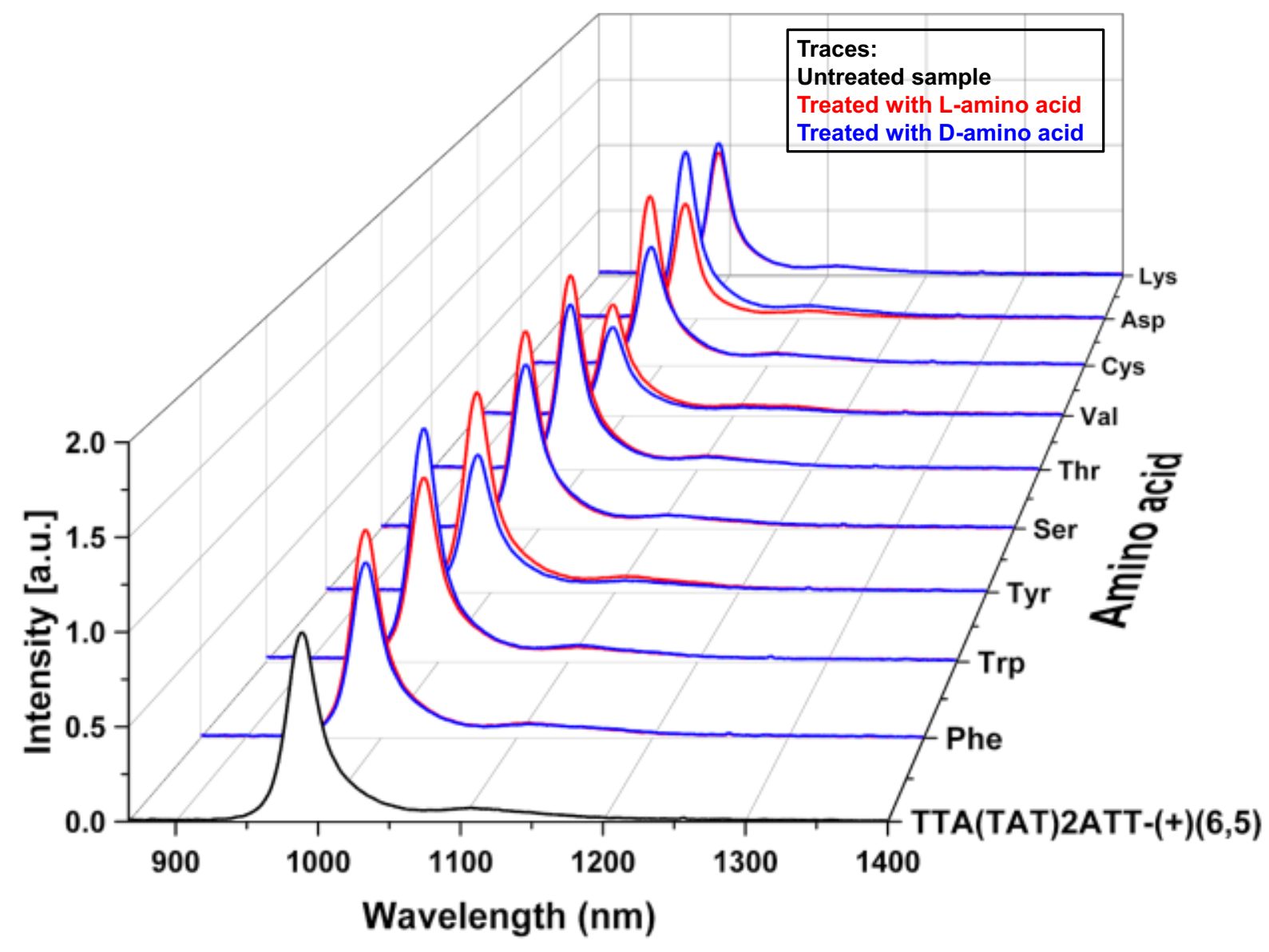

Figure S9 Waterfall plot of diastereomerically pure TTA(TAT) $)_{2}$ ATT-(+)(6,5) when treated with enantiomeric amino acids (excitation wavelength $=532 \mathrm{~nm}$ ). 


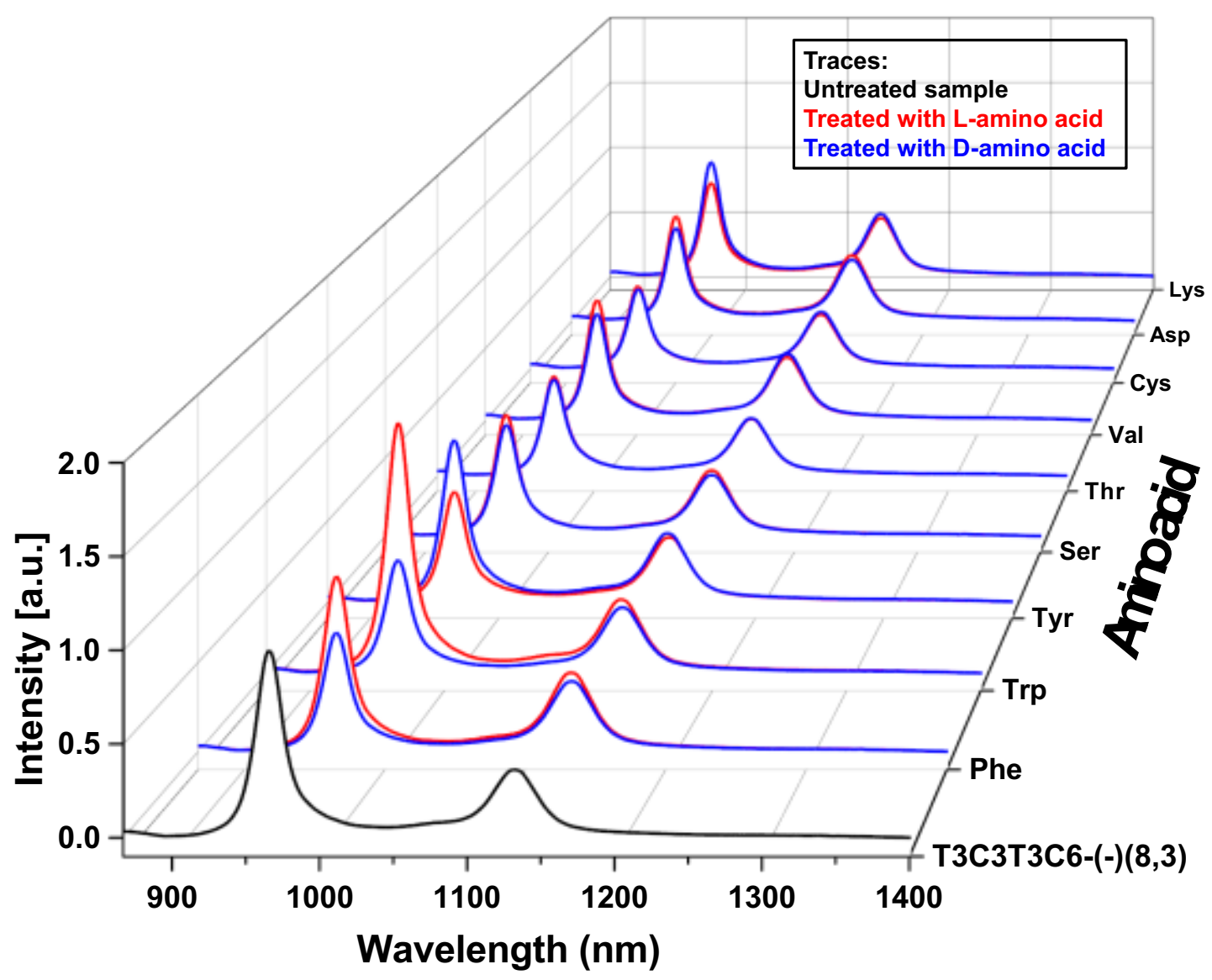

Figure S10 Waterfall plot of diastereomerically pure $T_{3} C_{3} T_{3} C_{6}-(-)(8,3)$ when treated with enantiomeric amino acids (excitation wavelength $=671 \mathrm{~nm}$ ). 


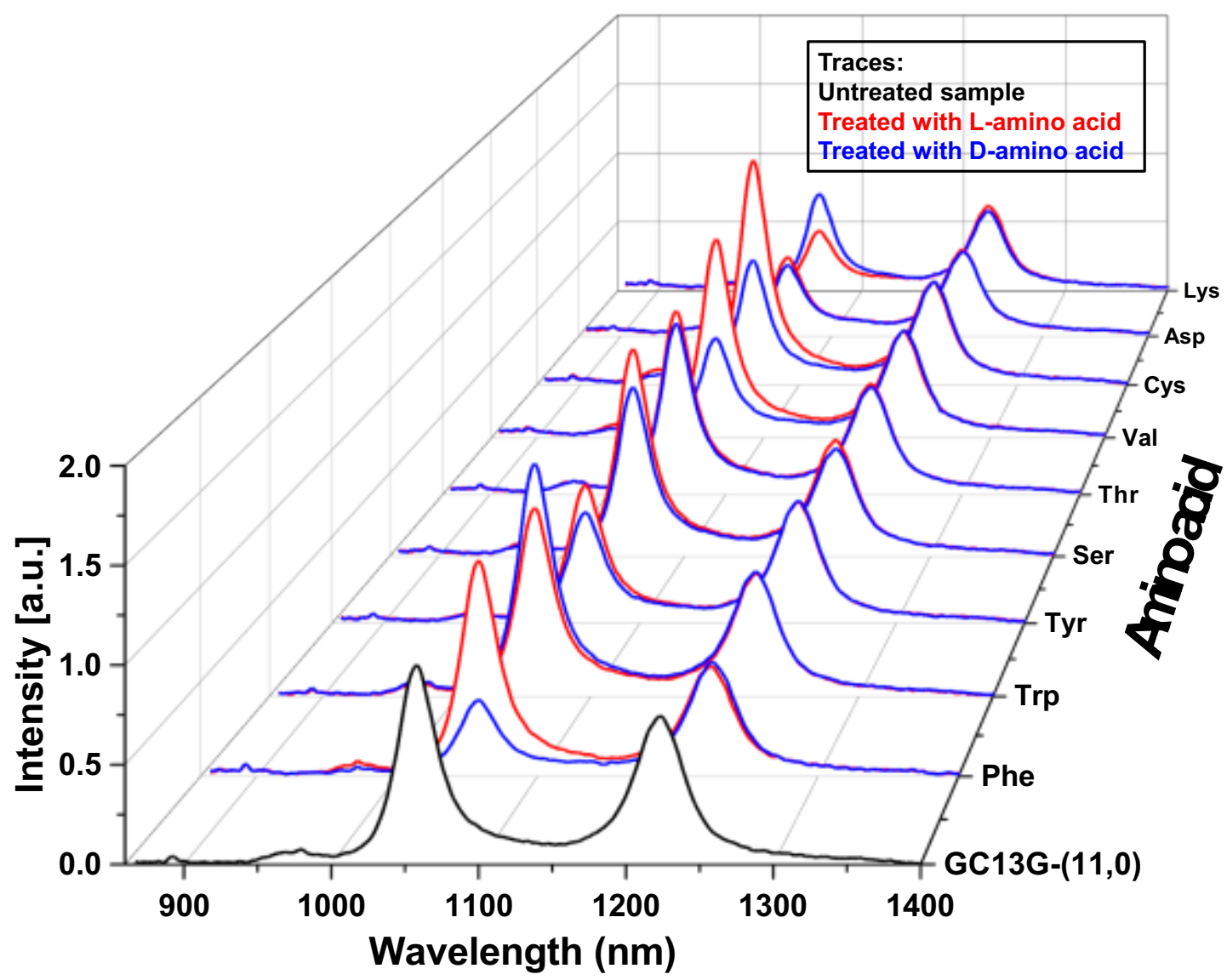

Figure S11 Waterfall plot of diastereomerically pure $\mathrm{GC}_{13} \mathrm{G}-(11,0)$ when treated with enantiomeric amino acids (excitation wavelength $=782 \mathrm{~nm})$. 


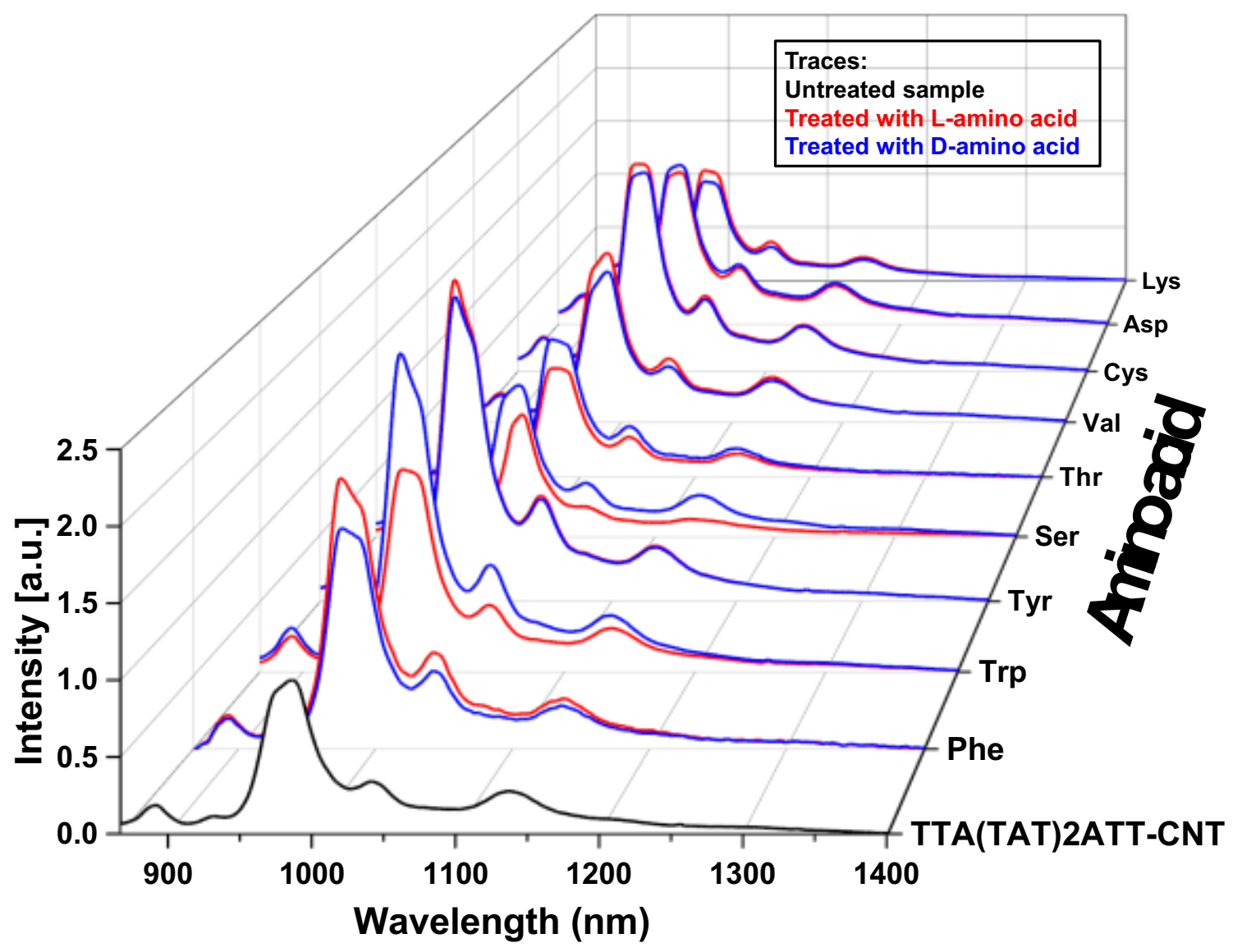

Figure S12 Waterfall plot of TTA (TAT) $)_{2}$ ATT-SWCNT dispersion when treated with enantiomeric amino acids (excitation wavelength $=671 \mathrm{~nm}$ ). 


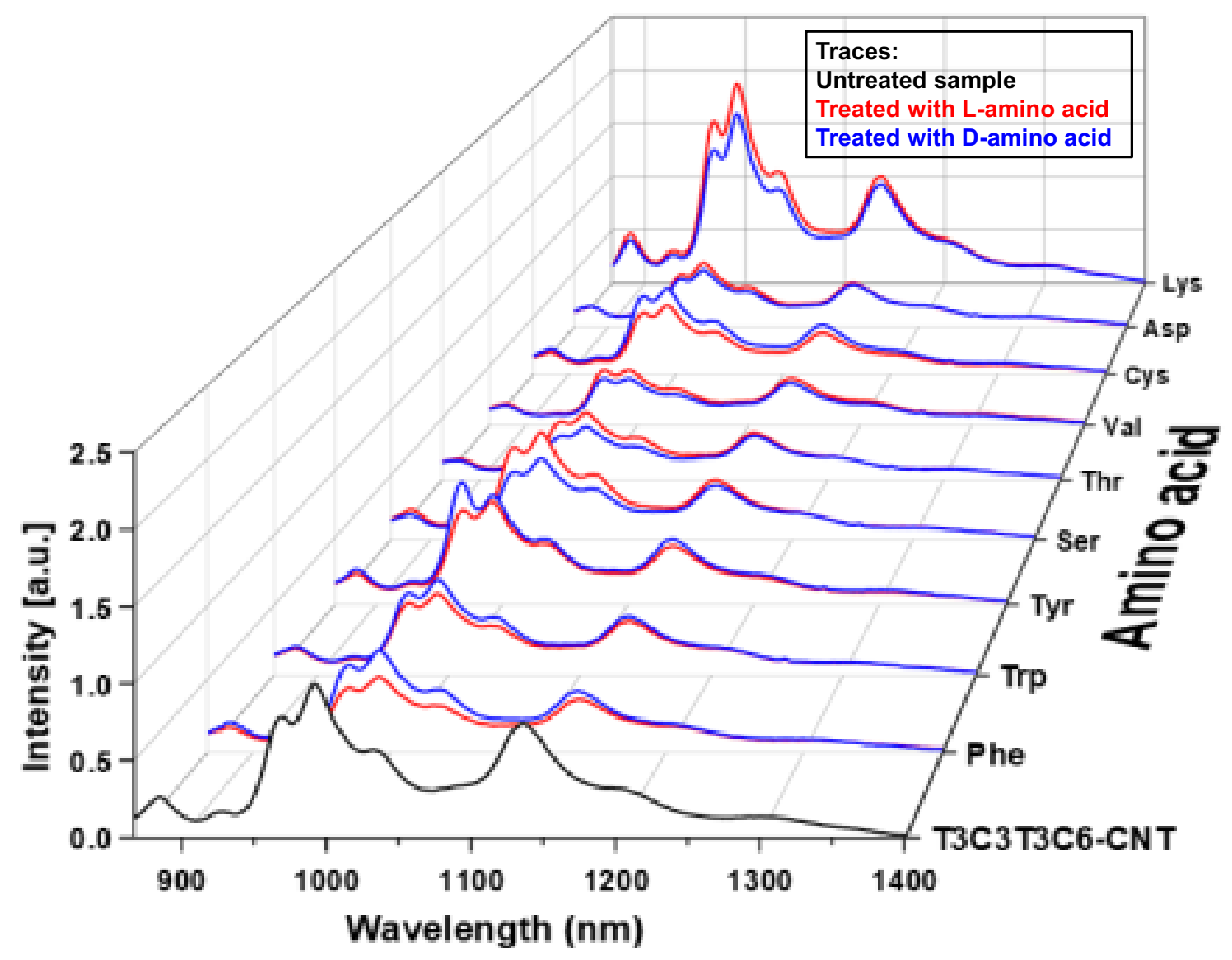

Figure S13 Waterfall plot of $\mathrm{T}_{3} \mathrm{C}_{3} \mathrm{~T}_{3} \mathrm{C}_{6}$-SWCNT dispersion when treated with enantiomeric amino acids (excitation wavelength $=671 \mathrm{~nm}$ ). 


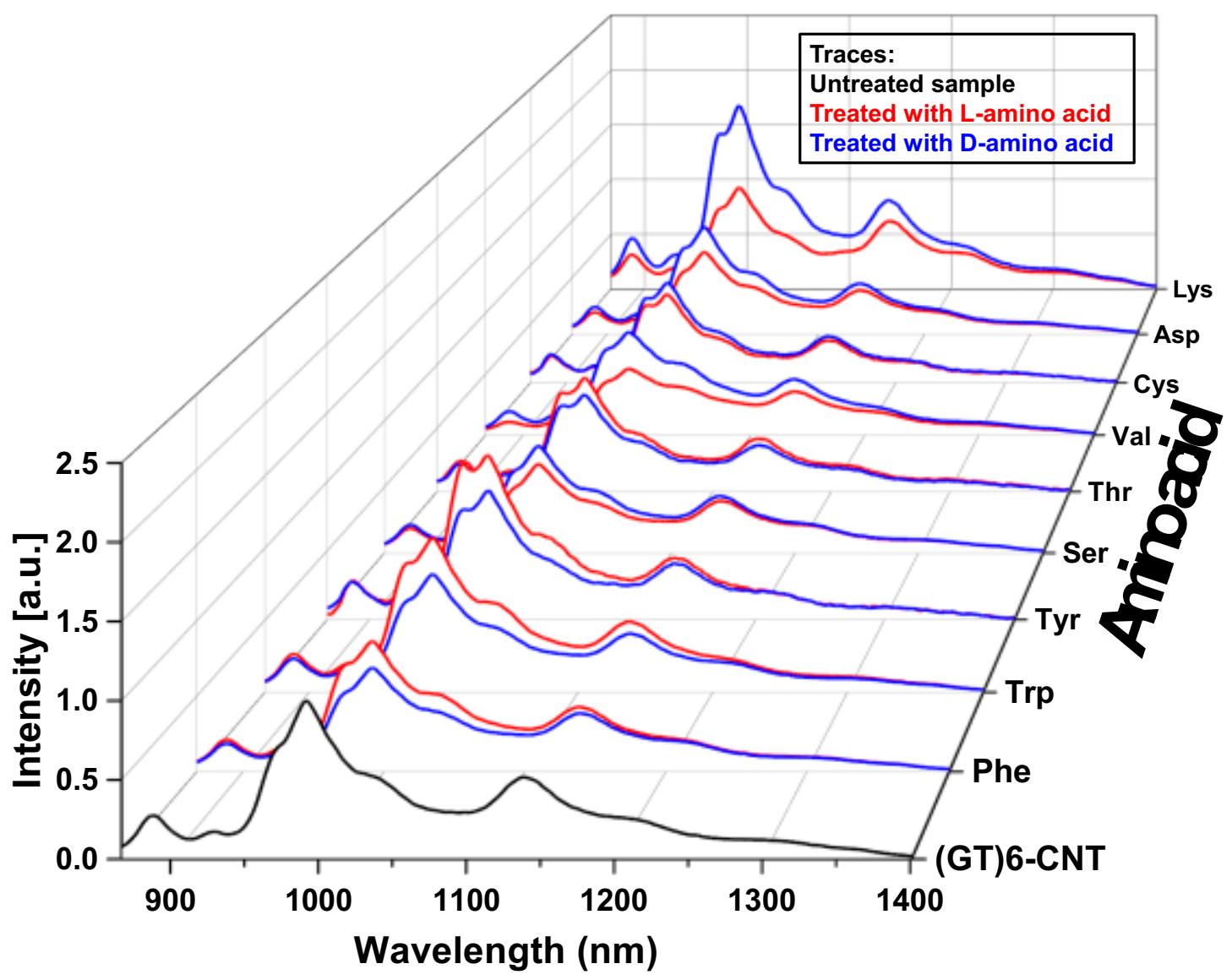

Figure S14 Waterfall plot of (GT) $)_{6}$-SWCNT dispersion when treated with enantiomeric amino acids (excitation wavelength $=671 \mathrm{~nm})$. 


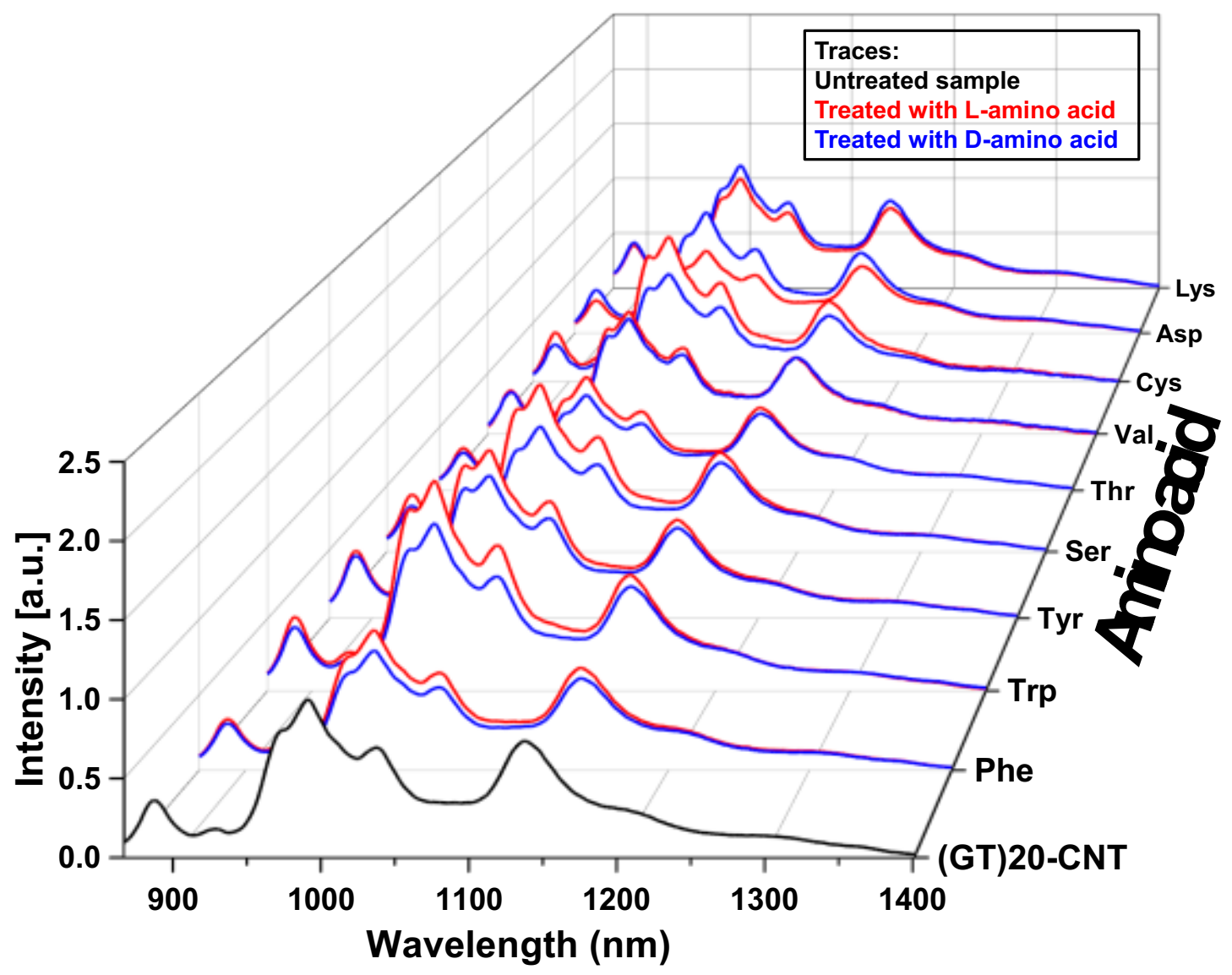

Figure S15 Waterfall plot of $(\mathrm{GT})_{20}$-SWCNT dispersion when treated with enantiomeric amino acids (excitation wavelength $=671 \mathrm{~nm}$ ). 


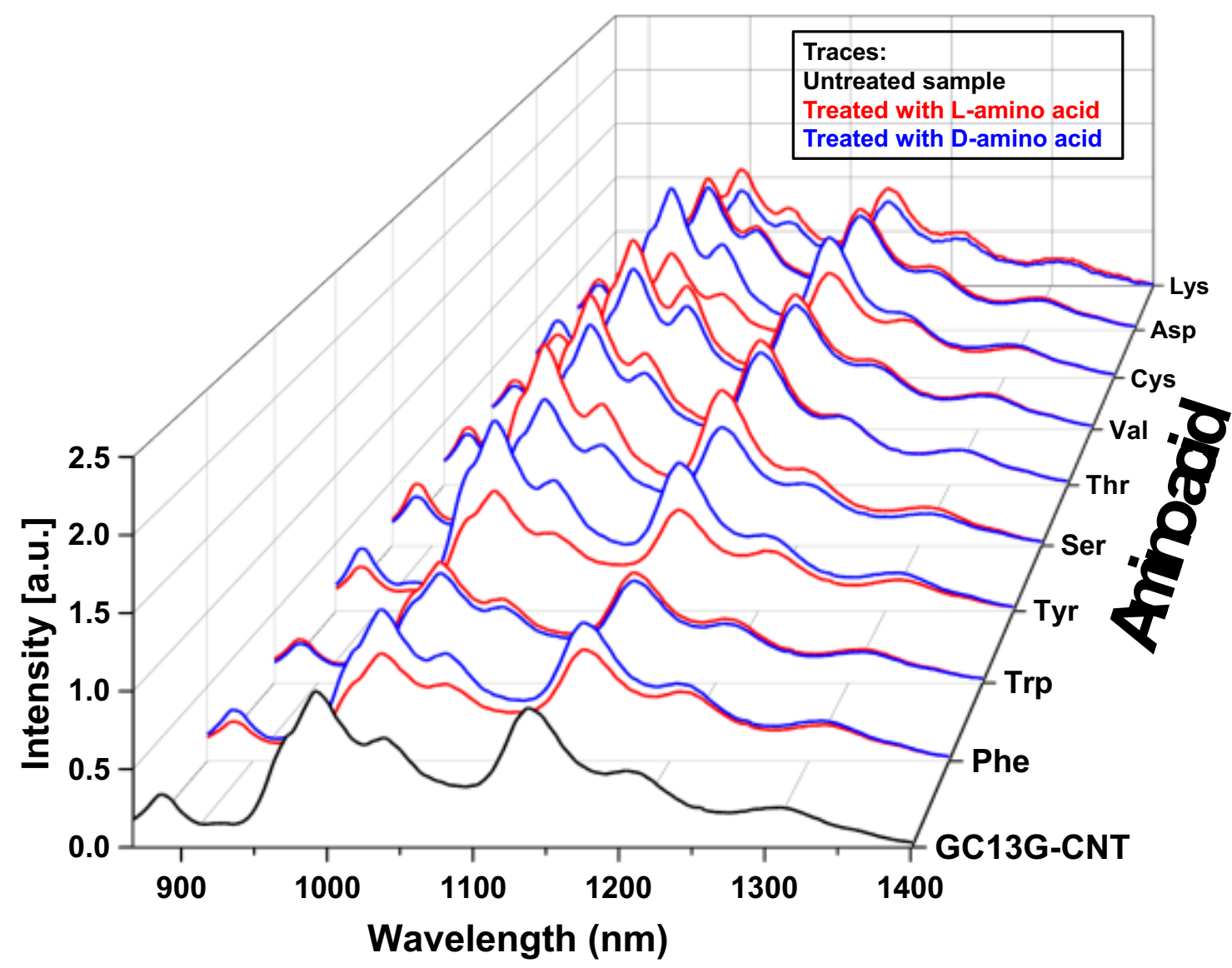

Figure S16 Waterfall plot of $\mathrm{GC}_{13} \mathrm{G}-\mathrm{SWCNT}$ dispersion when treated with enantiomeric amino acids (excitation wavelength $=671 \mathrm{~nm}$ ). 


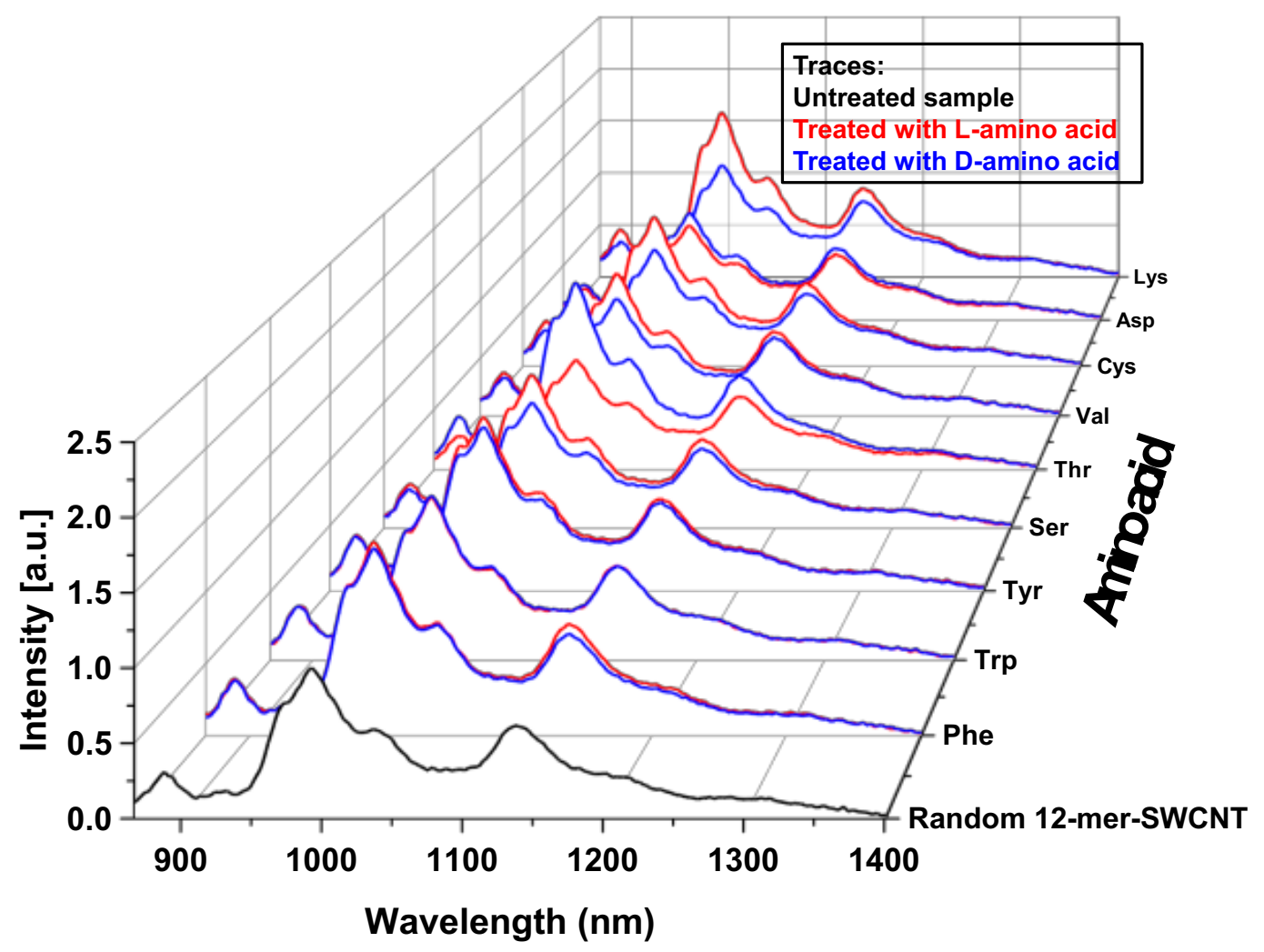

Figure S17 Waterfall plot of Random 12-mer-SWCNT dispersion when treated with enantiomeric amino acids (excitation wavelength $=671 \mathrm{~nm})$.

Figure S12 shows that TTA (TAT) 2 ATT-SWCNTs give large stereoselective responses to Trp and Ser. When mixtures of $\mathrm{T}_{3} \mathrm{C}_{3} \mathrm{~T}_{3} \mathrm{C}_{6}-\mathrm{SWCNT}$ and amino acid were probed, the PL responses (Figure $\mathrm{S} 13)$ at $(8,3)$ peak position $970 \mathrm{~nm}$ resembled the output we observed from enantioenriched $\mathrm{T}_{3} \mathrm{C}_{3} \mathrm{~T}_{3} \mathrm{C}_{6-}(-)(8,3)$. Figures S14 and S15 compare PL response profiles of $(\mathrm{GT})_{6}$ and $(\mathrm{GT})_{20^{-}}$ SWCNTs. Overall, the two profiles show sequence-length dependence in a non-trivial way. For example, Ser enantiomer pair show less PL differentiation in $(\mathrm{GT})_{6}$-SWCNT than in $(\mathrm{GT})_{20^{-}}$ SWCNT, but the trend is opposite for the Val enantiomer pair. Figure S16 shows PL response profile for $\mathrm{GC}_{13} \mathrm{G}-\mathrm{SWCNTs}$. Overall, this dispersion gives good resolution between enantiomers of amino acids, especially for Phe, Tyr, Ser, and Cys. Random 12-mer-SWCNT results shown in Figure S17 provides some insight into the mechanism of stereoselective response from DNASWCNTs. Zerze et al. have recently found by molecular dynamics simulations that the intrinsic chirality of the ssDNA dictates the helical wrapping around SWCNTs. ${ }^{11}$ This suggests that a random sequence would self-assemble into a specific chiral conformation irrespective of the SWCNT and should have varied affinities with enantiomers of chiral analytes. This study also correlates with the findings we observed with the achiral tube $\mathrm{GC}_{13} \mathrm{G}-(11,0)$ in Figure $\mathrm{S} 11$. When we treated random sequence 12-merCNT with amino acids, we indeed observed that enantioselective PL responses (Figure S17). While more direct experimental evidence is needed to confirm the conclusion of Zerze et al., our observation is consistent with their finding and suggests that the intrinsic chirality of DNA is sufficient to give rise to stereoselective response of DNA-SWCNTs . 
VIII. Response spectrum calculated to show chirality-dependence response when TTA $($ TAT) 2 ATT-SWCNT was treated with tryptophan (Trp) (top) and serine (Ser) (bottom) enantiomers
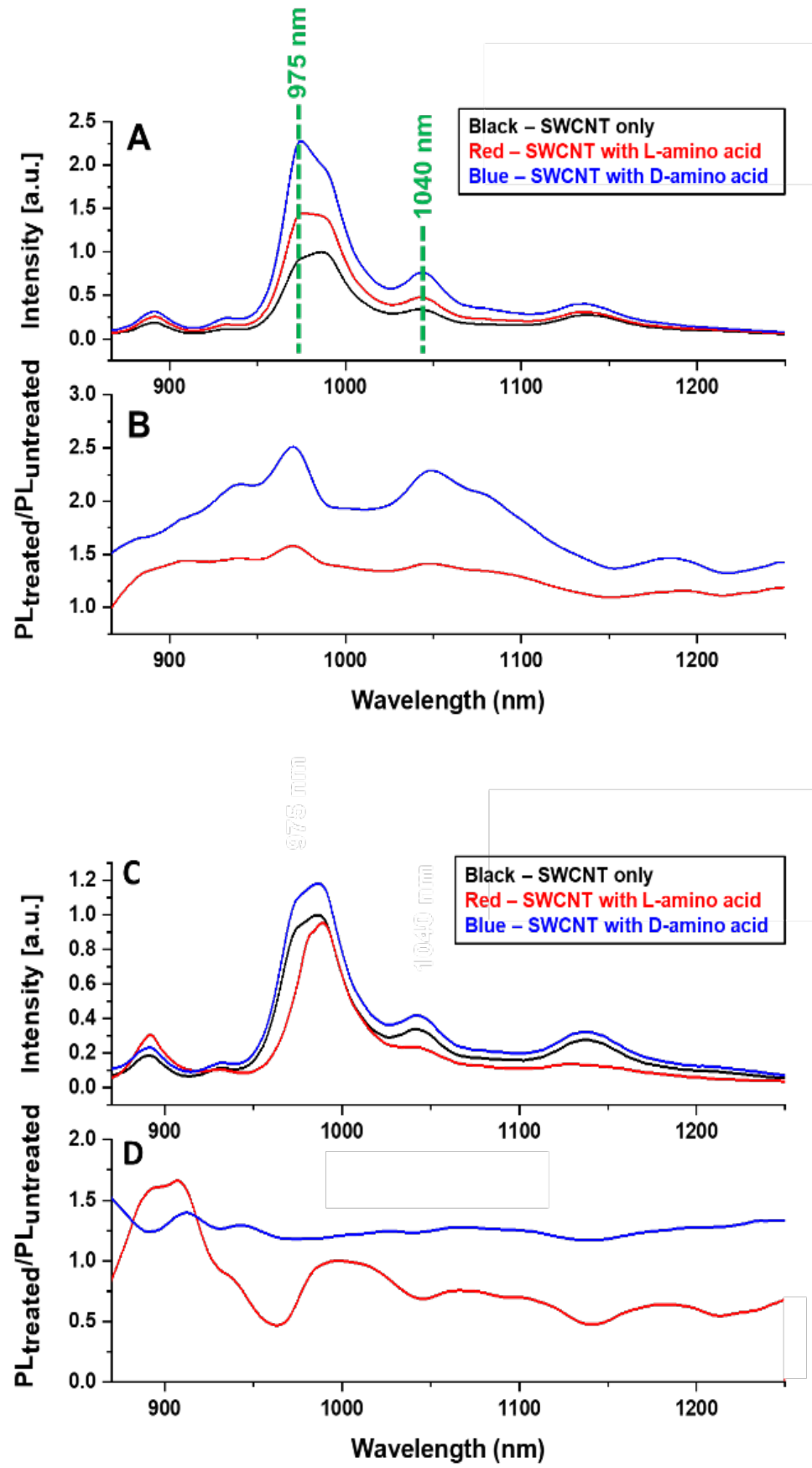

Figure S18 A) Stereoselective PL observed (top) and B) response spectrum calculated (bottom) when L (red) and Denantiomers (blue) of Trp were added to TTA (TAT)2 ATT-SWCNT dispersion. C) Stereoselective PL observed (top) and D) response spectrum calculated (bottom) when $L$ (red) and D-enantiomers (blue) of Ser were added to TTA (TAT)2 ATTSWCNT dispersion (excitation wavelength $=671 \mathrm{~nm}$ ). 


\section{References:}

(1) Ao, G.; Streit, J. K.; Fagan, J. A.; Zheng, M. Differentiating Left- and Right-Handed Carbon Nanotubes by DNA. J. Am. Chem. Soc. 2016, 138 (51), 16677-16685. https://doi.org/10.1021/jacs.6b09135.

(2) Lyu, M.; Meany, B.; Yang, J.; Li, Y.; Zheng, M. Toward Complete Resolution of DNA/Carbon Nanotube Hybrids by Aqueous Two-Phase Systems. J. Am. Chem. Soc. 2019, 141 (51), 20177-20186. https://doi.org/10.1021/jacs.9b09953.

(3) Ao, G.; Khripin, C. Y.; Zheng, M. DNA-Controlled Partition of Carbon Nanotubes in Polymer Aqueous Two-Phase Systems. J. Am. Chem. Soc. 2014, 136 (29), 10383-10392. https://doi.org/10.1021/ja504078b.

(4) Min Lyu. Chirality Sorting of DNA-Wrapped Single-Wall Carbon Nanotubes Based on Aqueous Two-Phase Systems (PhD Thesis), Peking University, 2020.

(5) Zheng, M.; Jagota, A.; Strano, M. S.; Santos, A. P.; Barone, P.; Chou, S. G.; Diner, B. A.; Dresselhaus, M. S.; McLean, R. S.; Onoa, G. B.; Samsonidze, G. G.; Semke, E. D.; Usrey, M.; Watts, D. J. Structure-Based Carbon Nanotube Sorting by Sequence-Dependent DNA Assembly. Science. 2003, 302 (5650), 1545-1548.

https://doi.org/10.1126/science.1091911.

(6) Tu, X.; Manohar, S.; Jagota, A.; Zheng, M. DNA Sequence Motifs for Structure-Specific Recognition and Separation of Carbon Nanotubes. Nature 2009, 460 (7252), 250-253. https://doi.org/10.1038/nature08116.

(7) Beyene, A. G.; Alizadehmojarad, A. A.; Dorlhiac, G.; Goh, N.; Streets, A. M.; Král, P.; Vuković, L.; Landry, M. P. Ultralarge Modulation of Fluorescence by Neuromodulators in Carbon Nanotubes Functionalized with Self-Assembled Oligonucleotide Rings. Nano Lett. 2018, 18 (11), 6995-7003. https://doi.org/10.1021/acs.nanolett.8b02937.

(8) Landry, M. P.; Yang, D.; Yang, S. J.; Del Bonis-O’Donnell, J. T.; Pinals, R. L. Mitigation of Carbon Nanotube Neurosensor Induced Transcriptomic and Morphological Changes in Mouse Microglia with Surface Passivation. ACS Nano 2020, 14 (10), 13794-13805. https://doi.org/10.1021/acsnano.0c06154.

(9) Zhang, J.; Landry, M. P.; Barone, P. W.; Kim, J. H.; Lin, S.; Ulissi, Z. W.; Lin, D.; Mu, B.; Boghossian, A. A.; Hilmer, A. J.; Rwei, A.; Hinckley, A. C.; Kruss, S.; Shandell, M. A.; Nair, N.; Blake, S.; Şen, F.; Şen, S.; Croy, R. G.; Li, D.; Yum, K.; Ahn, J. H.; Jin, H.; Heller, D. A.; Essigmann, J. M.; Blankschtein, D.; Strano, M. S. Molecular Recognition Using Corona Phase Complexes Made of Synthetic Polymers Adsorbed on Carbon Nanotubes. Nat. Nanotechnol. 2013, 8 (12), 959-968. https://doi.org/10.1038/nnano.2013.236.

(10) Mann, F.; Herrmann, N.; Meyer, D.; Kruss, S. Tuning Selectivity of Fluorescent Carbon Nanotube-Based Neurotransmitter Sensors. Sensors 2017, 17 (7), 1521. https://doi.org/10.3390/s17071521.

(11) Zerze, G. H.; Stillinger, F. H.; Debenedetti, P. G. The Handedness of DNA Assembly around Carbon Nanotubes Is Determined by the Chirality of DNA. J. Phys. Chem. B 2020, 
124 (26), 5362-5369. https://doi.org/10.1021/acs.jpcb.0c02816.

(12) Cantor, C. R.; Schimmel, P. R. Biophysical Chemistry: Part III: The Behavior of Biological Macromolecules; Freeman \& Company, W. H.: New York, 1980. 